\title{
Art. 21 da LINDB \\ Indicando consequências e regularizando atos e negócios
}

\author{
Article 21 of LINDB \\ Indicating consequences and \\ regularizing public acts and \\ arrangements
}

\author{
José Vicente Santos de Mendonça
}

\section{RESUMO}

$\mathrm{O}$ artigo pretende auxiliar na interpretação das normas extraídas a partir do art. 21 do Decreto-Lei no 4.567/42 - Lei de Introdução às Normas do Direito Brasileiro (LINDB). De início, o texto contextualiza o art. 21 da LINDB junto ao debate sobre o controle público. Então, indica o que poderiam ser consequências jurídicas e administrativas, e reflete sobre como se poderia indicá-las numa decisão administrativa ou judicial. Em

\footnotetext{
Professor de Direito Administrativo da Universidade do Estado do Rio de Janeiro. Professor do Mestrado e do Doutorado da Universidade Veiga de Almeida (RJ). Doutor e Mestre em Direito Público (UERJ). Master of Laws (Harvard). Procurador do estado do Rio de Janeiro e advogado. E-mail: <josevicente@josevicentemendonca.com.br>. Agradeço aos estagiários João Vitor Silva, João Galdi e Daian Borges, e ao doutor André Tosta, por leituras e/ou revisões em versões anteriores do texto. Críticas são apenas para mim; elogios são para todos.
} 
seguida, o artigo cogita sobre o que poderia ser o dever de regularização proporcional, exigido pelo art. 21, par. único, da LINDB. Ao final, são indicados alguns possíveis aspectos polêmicos associados à incidência das normas objeto de estudo.

\section{PALAVRAS-CHAVE}

Consequencialismo - LINDB - interpretação jurídica - regularização

\section{ABSTRACT}

My paper aims helping interpreting article 21 of Decreto-Lei no 4.567/42 Statute of Introduction to Brazilian Law Norms. At first, I try to integrate article 21 into a broader debate about Government controls. Then, I establish what could be taken as legal and administrative consequences, and reflect on how one could indicate them on a legal opinion. In the next section, I suggest what could be a duty on 'proportional validation' (as that of article 21, paragraph, of Decreto $\mathrm{n}^{\mathrm{o}} 4.567 / 42$ ). Lastly, I contend with some of possible problems and difficulties associated with real-world application of article 21 of Decreto-Lei ํํำ.567/42.

\section{KEYWORDS}

Consequentialism - LINDB - legal interpretation - regularization.

Art. 21. A decisão que, nas esferas administrativa, controladora ou judicial, decretar a invalidação de ato, contrato, ajuste, processo ou norma administrativa deverá indicar de modo expresso suas consequências jurídicas e administrativas.

Parágrafo único. A decisão a que se refere o caput deste artigo deverá, quando for o caso, indicar as condições para que a regularização ocorra de modo proporcional e equânime e sem prejuízo aos interesses gerais, não se podendo impor aos sujeitos atingidos ônus ou perdas que, em função das peculiaridades do caso, sejam anormais ou excessivos. 


\section{Introdução}

\subsection{A cultura do hipercontrole público}

O consequencialismo chegou ao Direito Público brasileiro. E chegou de modo que nos é bem característico: reagindo, por artigo de lei, a algo. É que parte das alterações trazidas pela lei no 13.655 , de abril de 2018, ao Decreto-lei no 4.567/42 - a Lei de Introdução às Normas do Direito Brasileiro (LINDB) -, pretende reagir à cultura do hipercontrole público que tomou conta do Brasil dos últimos tempos. Antes de falar sobre a alteração da lei, vale a pena, então, entender o contexto no qual ela se insere.

Como toda cultura, a cultura do hipercontrole não é só o que está nas normas, mas é, especialmente, um modo de se compreender e de se fazer algo. ${ }^{2}$ Aqui se vai identificá-la a partir de cinco aspectos: o controle como (i) vagueza; como (ii) opinião; como (iii) performance; como (iv) disputa; e, afinal, como (v) incremento. ${ }^{34}$

Em razão da existência de normas habilitadoras do controle com tipos vagos, e de certa cultura principialista hoje comum no Direito, percebe-se o exercício do controle público como (i) vagueza. ${ }^{5}$ Assim, por exemplo, o art. 11 da Lei de Improbidade Administrativa, em seu caput, informa que constitui ato de improbidade administrativa qualquer ação ou omissão que viole os deveres de honestidade, imparcialidade, legalidade, e de lealdade às instituições. ${ }^{6}$ É plausível supor que, com base em categorias tão amplas, parte do exercício do controle público esconda simples discordâncias de opiniões entre controladores e controlados - um (ii) controle de opinião sobre a interpretação jurídica de normas ou de práticas.

2 Sobre o peso e os instrumentos da cultura no e do Direito Administrativo, v. Sunstein; Vermeule (2018).

3 O diagnóstico foi inicialmente elaborado para apresentação em palestra na Associação de Funcionários do BNDES ocorrida no dia 25 de agosto de 2017. A apresentação se chama "Seis Propostas para o Novo Decênio do Controle Público." O vídeo da apresentação está disponível em: <https://www.youtube.com/watch?v=lPzVRURTsuM>. Acesso em: 15 set. 2018. Cortei um dos itens do diagnóstico - eram, de início, seis, como se pode imaginar do título da apresentação -, e, aqui, não estou ingressando nas propostas de solução. Texto com abordagem parecida (embora com diagnósticos ligeiramente diferentes) é o de Marques Neto; De Palma (2017).

4 Na doutrina estrangeira, cf. Halachmi (2014).

5 O fenômeno é diagnosticado em SUNDFELD, 2015, p. 60 e ss.

${ }_{6}$ Lei $\mathrm{n}^{\mathrm{o}}$ 8.429/92, art. 11. Constitui ato de improbidade administrativa que atenta contra os princípios da administração pública qualquer ação ou omissão que viole os deveres de honestidade, imparcialidade, legalidade, e lealdade às instituições, e notadamente: [...]. 
Se o controle se faz a partir da opinião jurídica sobre tipos abertos, tornase estratégico que controladores conquistem boa reputação junto à sociedade. ${ }^{7}$ Logo, há incentivos para que o controle se realize de modo performático; para que, mercê de atuações espalhafatosas, perceba-se publicamente sua existência e, daí, sua força. ${ }^{8}$ É o controle como (iii) performance.

Outra estratégia de obtenção de poder é disputá-lo junto a iguais. Dada a existência, em nosso país, de diversas instâncias, órgãos e entidades de controle, a cultura do hipercontrole favorece a técnica do desacordo-comopoder. Numa cadeia de autorizações, quem manda de fato não é quem permite, mas quem nega. É a ele que o particular terá de apresentar explicações. Eis o controle como (iv) disputa. ${ }^{9}$

Em função da carência de dados amplos a respeito dos efeitos do controle público, ${ }^{10}$ dos incentivos para a performance, e do número de instâncias, pode-se intuir que existam incentivos eleitorais e funcionais à criação de novos tipos, de penalidades mais severas, e, quiçá, de novos órgãos. É o controle como (v) incremento: controlar bem é, sob essa estrutura de incentivos, controlar sempre mais.

O hipercontrole público só funciona de modo adequado para certos controladores - os que hajam obtido vitórias recentes. Para os demais controladores, e, significativamente, para a sociedade, é possível que, entre prós e contras, estejamos perdendo dinheiro e potencial. Contra a cultura do hipercontrole é que se pretende afirmar a prática do consequencialismo jurídico, da qual a LINDB busca ser referencial normativo.

\subsection{O consequencialismo jurídico e a LINDB. Roteiro do artigo}

O significado do consequencialismo é discutido em diversos campos do conhecimento, como na teoria da argumentação e na ética. ${ }^{11}$ Muitos desses

7 É que, salvo alguma determinação normativa específica, é essencialmente isso que lhes garantirá que sua opinião triunfe sobre as opiniões concorrentes.

8 No que diz respeito à atuação do Supremo Tribunal Federal, destaca-se análise relacionada aos efeitos da introdução da TV Justiça e do televisionamento das sessões de julgamento em Fonte (2016).

9 Há vantagens e desvantagens na competição entre controladores. Pode-se permitir a eclosão de visões diferentes, que agreguem mais informação ao pool disponível. Por outro lado, desvantagem óbvia é a insegurança jurídica causada pela descoordenação.

10 Pode-se falar, aqui, numa outra característica da cultura do hipercontrole: o controle como impressão. Faltam dados abrangentes e imparciais a respeito dos efeitos do controle - mas não faltam juízos impressionistas.

11 DARWALL, 2008. 
debates podem não interessar ao operador jurídico. De modo simples, pode-se dizer que o consequencialismo é característica de certa postura, interpretativa ou cognitiva, tendente a considerar as consequências de ato, teoria ou conceito. O consequencialismo jurídico é, por sua vez, postura interpretativa que considera, como elemento significativo da interpretação do Direito, as consequências de determinada opção interpretativa. ${ }^{12}$ Parece ser nesse sentido abrangente que a LINDB se aproxima ao tema.

A julgar pela justificativa do projeto de lei que viria a se tornar a Lei $\mathrm{n}^{\mathrm{o}} 13.655 / 18,{ }^{13}$ e, ainda, pelas manifestações dos defensores de sua aprovação, ${ }^{14}$ o consequencialismo jurídico de que se imbui a LINDB busca servir como freio a certos aspectos da cultura do hipercontrole. Ao mesmo tempo, é preciso entender adequadamente como suas normas podem incidir aos casos, sob pena de ser parte do mal cuja cura se buscava ser.

O presente texto pretende auxiliar na interpretação adequada da LINDB. Para tanto, ele se foca nas normas jurídicas construídas a partir do art. 21, caput e parágrafo único. Os tópicos se dividem da seguinte forma: o item 2.1 dedicase à compreensão do que são as consequências jurídicas e administrativas mencionadas no art. 21, caput. Em seguida, o item 2.2 reflete sobre como elas poderão ser indicadas pelo julgador. O item 2.2 cuida das normas construídas a partir do parágrafo único do artigo 21. O item 3 analisa três aspectos polêmicos suscitados pela norma. O item 4 retoma, em parágrafos, as ideias desenvolvidas no texto.

\section{Interpretando o art. 21 da LINDB}

\subsection{O que são consequências jurídicas e administrativas}

$\mathrm{O}$ art. 21, caput, possui a seguinte redação: "A decisão que, nas esferas administrativa, controladora ou judicial, decretar a invalidação de ato, contrato, ajuste, processo ou norma administrativa, deverá indicar de modo expresso suas consequências jurídicas e administrativas." A norma exige a

Sobre o ponto, em abordagem ampla, seja concedida a referência a MENDONÇA, 2018, p. 23103 (primeiro capítulo).

13 Disponível em: <https://legis.senado.leg.br/sdleg-getter/documento?dm=2919883\&dispositio $\mathrm{n}=$ inline $>$. Acesso em: 15 set. 2018.

14 SUNDFELD, 2017. 
indicação expressa, na decisão de invalidação, de suas consequências jurídicas e administrativas. O que elas vêm a ser?

Numa primeira aproximação ao tema, pode-se dizer que consequências jurídicas são estados futuros associados à interpretação ou à aplicação do Direito. O Judiciário invalida a desapropriação. Uma das consequências jurídicas imediatas é o dever jurídico de se devolver a indenização ao expropriante. Servidor estável tem sua demissão invalidada administrativamente; consequência jurídica imediata é a reintegração ao cargo. ${ }^{15}$ Decisão judicial invalida norma de agência que proíbe a comercialização de medicamento; consequência lógico-jurídica é a liberação do comércio.

Também nessa primeira impressão, consequências jurídicas seriam estados futuros associados à atuação pública. Em muitos casos, a consequência jurídica diz do dever ou do direito que surge a partir da decisão, e a consequência administrativa é sua decorrência material. Com a invalidação da demissão do servidor estável surge o direito à reintegração; com o exercício do direito, consequência administrativa é o apostilamento do retorno ao cargo. No exemplo da liberação do medicamento, consequência administrativa é a sustação de operações da agência com o propósito de recolher o produto.

As consequências a que norma do art. 21 se refere são estados de fato e de Direito (i) admissíveis pela Constituição de 1988 e exequíveis. Consequências que impliquem a instrumentalização de direitos fundamentais não são admissíveis. A norma do art. 21 não é, apenas, dever expresso de fundamentação de decisão (v. tópico a seguir). Há outra norma que dele se extrai: o julgador não poderá invalidar o ato, negócio ou norma administrativa quando, disso, decorrerem estados jurídicos ou administrativos inconstitucionais elou inexequíveis. Figure-se exemplo. A invalidação de decreto sobre administração prisional implicará a desativação do presídio estadual e a liberação de mil presos. A consequência administrativa é inexequível e funciona como trava à invalidação pura e simples. ${ }^{16}$

As consequências jurídicas e administrativas a serem indicadas devem ser, ainda, (ii) certas e prováveis, e não apenas plausíveis. Embora algum

15 Para o servidor público federal, cf. art. 28 da Lei no 8.112/90: reintegração é a reinvestidura do servidor estável no cargo anteriormente ocupado, ou no cargo resultante de sua transformação, quando invalidada a sua demissão por decisão administrativa ou judicial, com ressarcimento de todas as vantagens.

16 A decisão não precisa, é claro, ser apenas pela invalidação ou pela validação. O julgador pode estabelecer alguns parâmetros para o cumprimento da decisão e que possam "salvá-la" da inexequibilidade (ex., a transferência dos presos para estabelecimento prisional capaz de os receber). 
intuicionismo esteja envolvido em categorias quetais, a diferença entre aquelas e essa está na certeza da ocorrência. É certo que, a partir de medida de decretação de indisponibilidade de bens de sociedade empresária de capital aberto, haverá desvalorização de suas ações. ${ }^{17}$ É provável que, da interdição sanitária de pequeno bar por longo período, resulte a quebra da empresa o que proibiria, por exemplo, interdições por períodos extensos. É plausível cogitar que seus ex-proprietários, portugueses idosos afundados em dívidas, busquem retornar a Portugal - mas não é certo nem provável. ${ }^{18}$

Consequências jurídicas e administrativas são estados (iii) imediatos e imediatamente futuros, mas não os remotos no tempo. Esta característica se liga à discussão sobre causalidade. O Direito brasileiro adota, para a responsabilidade civil, a teoria da causalidade direta e imediata (art. 403 do Código Civil $\left.{ }^{19}\right)$. Este entendimento foi afirmado pelo STF em vários julgados..$^{20}$ O debate na responsabilidade civil opera com a categoria do resultado danoso. Mas a lição pode ser estendida à identificação das consequências a serem consideradas/indicadas na decisão a respeito da invalidade de ato, negócio ou norma. Em nosso ordenamento, a não ser que haja previsão em contrário, causa é o evento que necessariamente produz o resultado, e, daí, a consequência. Consequência administrativa ou jurídica é o efeito direto da decisão de invalidade. ${ }^{21}$

17 E isso não é necessariamente inconstitucional, pois outros bens jurídicos podem estar sendo adequadamente satisfeitos pela decisão.

18 Apesar de não haver divisão exata ente as categorias, é seguro dizer que há consequências mais certas, prováveis e plausíveis do que outras; o referencial é suficientemente simples para ser operacional. Numa ciência social aplicada cuja base é a linguagem - como o Direito -, parâmetros comparativos formulados a partir de expressões como essas é o que de melhor se pode fazer. A respeito do ponto, v. Alexy (2003).

19 Art. 403. Ainda que a inexecução resulte de dolo do devedor, as perdas e danos só incluem os prejuízos efetivos e os lucros cessantes por efeito dela direto e imediato, sem prejuízo do disposto na lei processual.

20 Veja-se, por exemplo: "Em nosso sistema jurídico, como resulta do disposto no artigo 1.060 do Código, a teoria adotada quanto ao nexo de causalidade é a teoria do dano direto e imediato, também denominada teoria da interrupção do nexo causal. Não obstante aquele dispositivo da codificação civil diga respeito à impropriamente denominada responsabilidade contratual, aplica-se ele também à responsabilidade extracontratual, inclusive a objetiva, até por ser aquela em que, sem quaisquer considerações de ordem subjetiva, afasta os inconvenientes das outras duas teorias existentes: a da equivalência das condições e a da causalidade adequada" (STF, julg. 12 maio 1992, RE 130.764, rel. Min. Moreira Alves).

21 Registre-se que o uso jurisprudencial das teorias da causalidade é, por vezes, errático, tanto no Direito privado quanto no Direito público. Em muitos casos, de acordo com crítica de parte da doutrina, o magistrado escolhe a teoria da causalidade que melhor atende ao resultado que, no seu entender, satisfaz seu sentimento de justiça. "A observação das decisões judiciais revela que as cortes têm empregado ora uma teoria, ora outra, sem que se possa definir sequer um padrão de julgamento a partir dos diversos precedentes emitidos em um determinado 
Consequência jurídica ou administrativa é estado de fato em relação aos quais se possa indicar (iv) alguma base, lógica ou empírica, de evidenciação. Consequência não é palpite. É decorrência - lógica, jurídica, ou fática - da decisão. Caso de trate de decorrência fática, deve ser possível indicar-lhe alguma evidência empírica. Evidência empírica poder ser, por exemplo, relatórios produzidos por fontes imparciais; notas técnicas; manuais de boas práticas; pesquisas científicas.

Sintetizando as reflexões até aqui apresentadas, pode-se dizer que consequências jurídicas são estados imediatos e imediatamente futuros associados à interpretação ou à aplicação do Direito e que, certos ou prováveis, sejam exequíveis e admissíveis pela Constituição de 1988. Consequências administrativas são estados imediatos e imediatamente futuros, associados à atuação pública e que, certos ou prováveis, sejam igualmente exequíveis e admissíveis por nossa Constituição.

\subsection{Como indicar consequências}

A norma jurídica imediatamente construída a partir do texto do art. 21, caput, da LINDB, diz respeito à fundamentação das decisões de invalidação. O julgador deve indicar, de modo expresso, consequências jurídicas e administrativas que decorrem da invalidação. Ao analisar o que são consequências, já resolvemos parte do problema de como indicá-las. A julgadora deve indicar estados jurídicos e administrativos imediatamente futuros que, sendo constitucionais, ocorrerão ou provavelmente ocorrerão. Mas ainda há o que se falar.

Primeira observação: o julgador não deve - porque não teria como indicar todas as consequências jurídicas e administrativas da decisão. Ele só deve indicar as consequências mais importantes, seja em termos econômicos, político-administrativos e/ou sociais. Da invalidação de contrato administrativo de serviços de limpeza numa escola pública decorrerão um sem número de consequências jurídicas e administrativas, mas o que se exige é que apenas as mais importantes sejam indicadas (o custo da evitação da ilegalidade ao erário; estratégias de realocação de alunos etc.). Vale registrar que nem sempre haverá consequências jurídicas $e$ administrativas

ordenamento" (SCHREIBER, 2013, p. 63). Ainda, falando em "presunções clandestinas de causalidade", v. Potier (1996). 
significativas; pode haver uma ou outra, e, muito raramente, nenhuma delas. Esta circunstância - a inexistência de um ou outro tipo de consequência, ou de nenhuma - deve ser objeto de justificativa expressa do julgador.

Observação importante: a expectativa de qualidade do juízo sobre a certeza e o timing da consequência, e a respeito de sua evidenciação, muda de instituição julgadora para instituição julgadora. Instituições distintas possuem expertises distintas. Espera-se que órgãos judiciais identifiquem a plausibilidade e o tempo das consequências jurídicas com mais precisão do que órgãos administrativos. Exemplo: com a invalidação, por tribunal judicial, de contrato de parceria público-privada, espera-se que a decisão indique os deveres de restituição de pagamentos e de retorno de bens afetados, e se contratos acessórios são válidos. Por outro lado, espera-se que consequências administrativas sejam mais precisamente identificadas (e, daí, expressamente indicadas) por órgãos administrativos, respeitada, em cada caso, a atribuição de cada um. Decisão do CREA poderá indicar consequências para o mercado de cimento melhor do que decisão da Secretaria de Fazenda. Decisão do TCU poderá indicar consequências de um reequilíbrio de concessão melhor do que a decisão de juiz não especialista.

Para cumprir adequadamente a exigência, o julgador poderá se socorrer de técnicas de diálogos intra e extraprocessuais. ${ }^{22} \mathrm{O}$ foco é na redução da assimetria informacional. Quando se discutir invalidação, o contencioso administrativo/judicial poderá dirigir atenção ao estudo das consequências da decisão. Assim, ao pretender invalidar regulamento de telecomunicações que limita a radiofrequência, é recomendável que o julgador escute agentes econômicos (empresas do setor de telecomunicações), acadêmicos (grupos de pesquisa), membros da sociedade civil (associações de consumidores). Nem sempre tal nível de abrangência dialógica será recomendável ou, sequer, factível; mas fica o registro de que, nos dias de hoje, há técnicas processuais especialmente desenhadas para se aferir o impacto de decisões.

Em termos práticos, as consequências jurídicas e administrativas (ou sua ausência parcial ou total) podem ser destacadas como último capítulo da decisão. Claro que decisões em massa podem justificar argumentações em série, mas o importante é que sejam evidenciadas com suficiente base empírica. Repita-se: consequência não é palpite, é derivação lógico-jurídica ou cogitação empiricamente sustentada.

22 OLIVEIRA, 2003. 


\subsection{A regularização proporcional}

$\mathrm{O}$ art. 21, parágrafo único, está redigido da seguinte forma:

A decisão a que se refere o caput deste artigo deverá, quando for o caso, indicar as condições para que a regularização ocorra de modo proporcional e equânime e sem prejuízo aos interesses gerais, não se podendo impor aos sujeitos atingidos ônus ou perdas que, em função das peculiaridades do caso, sejam anormais ou excessivos.

Ele permite a construção de duas normas: a primeira, - tal como no caput-, norma que impõe dever formal, incidente sobre a fundamentação de certas decisões administrativas ou judiciais; a segunda, norma material, que incide sobre o conteúdo dessas decisões.

A primeira norma a ser construída a partir do art. 21, par. único, circunscreve-se ao início do texto ("A decisão a que se refere o caput deste artigo deverá, quando for o caso, indicar as condições para que [...]"). Ela se dirige à autoridade tomadora da decisão, seja judicial ou administrativa, e é norma que impõe dever específico de fundamentação: a indicação expressa das condições para exercício daquilo que chamaremos de regularização proporcional. Como é norma atinente à fundamentação da decisão, caso descumprida invalidará a decisão, por violação de lei federal (a própria LINDB - v. tópico abaixo).

O dever de indicação é dever prima facie, isto é, pode inexistir se as circunstâncias da invalidação não levem à necessidade da regularização proporcional. Pensemos, por exemplo, na invalidação de norma administrativa que se encontrava em vacatio. Em princípio, nenhum efeito foi gerado na esfera jurídica de ninguém. A decisão que a invalida não precisa indicar as condições para seus efeitos sejam proporcionais. A regularização do estado de coisas se dá com a simples retirada da norma ilegal do mundo jurídico.

$\mathrm{O}$ art. 21, par. único, possui outra norma. Ela afirma que, também quando for o caso (o "quando for o caso" aplica-se ao artigo como um todo ${ }^{23}$ ), a regularização deverá ocorrer, de modo proporcional e equânime, e sem

23 Em rigor, toda norma jurídica só se aplica "quando for o caso". Há, em todas elas, a possibilidade de que sejam interpretadas integrando-se-lhes uma "lacuna oculta por redução teleológica”, como diria Karl Larenz (LARENZ, 1997. p. 555 et seq.). Mas, de Karl Larenz, precisamos chegar ao Brasil: como sugere Seabra Fagundes, no Brasil "é preciso dizer tudo tintim por tintim, senão não se cumpre" (SEABRA FAGUNDES apud BARROSO, 2006, p. 42). 
prejuízo aos interesses gerais, não se podendo impor aos sujeitos atingidos ônus ou perdas que, em função das peculiaridades do caso, sejam anormais ou excessivos.

O que é regularização? É a (i) identificação, para envolvidos e terceiros, dos efeitos pós-invalidação. Assim, num exemplo, trata-se de identificar se, da anulação do contrato administrativo, haverá a preservação de algum de seus efeitos, e para quem. Em outro sentido, também admissível pelo texto da lei, ela pode ser o ato ou o efeito de tornar regular; ou seja, (ii) a construção das condições de possibilidade da validade jurídica do ato, negócio, processo ou norma.

A norma impõe que a regularização seja proporcional e equânime. Em primeiro lugar, observe-se que dever de regularização proporcional não significa exigência de que a regularização seja leniente ao particular. Proporcional significa logicamente adequado, menos restritivo diante de opções aptas a produzir resultados semelhantes (aspecto importante, mas esquecido ${ }^{24}$ ), e justificável à luz de custos e benefícios. ${ }^{25} \mathrm{E}$ "equânime" é cognato associado à ideia de fairness, de distribuição equivalente de cargas. Numa invalidação, não será possível descarregar todo o custo do erro - pois a invalidação é sempre fruto de erro: alguém não detectou a ilegalidade - no particular. Ele só poderá suportar os ônus e as perdas tidas como "normais" diante da "anormalidade" do caso: se se descobre vício de legalidade na licitação, o contrato é nulo, mas serviços prestados devem ser pagos.

Uma das formas mais imediatas de exercício do dever de regularização proporcional é por meio da criação de períodos de transição. Detecta-se ilegalidade insanável no ato municipal que autorizava feira-livre. A decisão que o invalidar deverá estabelecer prazo razoável para que deixe de produzir efeitos, quiçá para que se realize a prática de novo ato que o permita (ou para que se encontre novo local).

O dever de regularização não pode ser feito com prejuízo aos interesses gerais. Descobre-se vício na investidura de Oficial de Justiça: estarão invalidados todos os seus atos, com a desconstituição da coisa julgada em diversos casos? Certamente não. Sublinhe-se, a propósito, que interesses gerais não equivalem a interesses patrimoniais do Estado. $\mathrm{O}$ dever de regularização pode ter custo ao erário - mas é o custo de se fazer (o) direito.

24 É que, em abstrato, sempre se pode cogitar de possibilidades que sejam menos restritivas a direitos fundamentais. Mas o sentido do teste da necessidade é o de se perguntar se, dentre opções que produzem resultados semelhantes, há alguma que seja menos restritiva a direitos fundamentais. A respeito, v. Afonso da Silva (2002).

25 PULIDO, 2007. 


\section{Aspectos polêmicos}

Três questões cercam a interpretação e a aplicação do art. 21, caput, e de seu parágrafo: (i) será que tribunais administrativos, cortes de contas e o Judiciário são capazes de adiantar consequências? (ii) Será que, por força de exigência suprarrogatória, o cumprimento do art. 21 tornar-se-ia mera retórica? (iii) Como poderá ser feito o controle judicial do art. 21?

Comecemos com a mais imediata, e que justificou críticas desde quando a alteração na LINDB era projeto de lei: (i) será que a exigência do caput do art. 21 é suprarrogatória? A resposta depende de quão exatas se espera que sejam as consequências indicadas. Se se espera que as consequências devam ser indicadas em nível ótimo de ocorrência e de exatidão, então a norma é impossível. Nenhum julgador possui bola de cristal. ${ }^{26}$

Por outro lado, em várias ocasiões julgadores são chamados a formular decisões tomando por base a consideração de consequências, e os resultados têm sido, na média, aceitáveis. ${ }^{27} \mathrm{O}$ art. 15 da lei do mandado de segurança autoriza a suspensão da liminar, ou da sentença, quando ela afetar a ordem, saúde, economia ou segurança públicas. ${ }^{28} \mathrm{O}$ dispositivo exige que o magistrado revisor analise não o conteúdo jurídico do julgado, mas, apenas, as consequências da decisão. Na suspensão de segurança, o revisor não funciona como um juiz "de Direito", mas como um administrador consequencialista de decisões alheias. O art. 27 da lei $n^{0}$ 9.868/99, nos casos em que aplicável, sugere que o STF identifique consequências para, depois, atribuir eficácia à declaração de inconstitucionalidade. ${ }^{29}$ Aliás, boa parte do ativismo - que não é só judicial, mas é de todas as instituições de controle - funda-se numa postura consequencialista.

26 Isso na implausível hipótese de bolas de cristal conseguirem ser algo mais do que peso de papel.

27 Ou seja: na média, os julgadores (aqui, juízes) têm demonstrado competência razoável acerca de como interpretar e aplicar normas que lhes impõe a consideração de consequências.

28 Lei $\mathrm{n}^{\mathrm{o}}$ 12.016/09, art. 15: Quando, a requerimento de pessoa jurídica de direito público interessada ou do Ministério Público e para evitar grave lesão à ordem, à saúde, à segurança e à economia públicas, o presidente do tribunal ao qual couber o conhecimento do respectivo recurso suspender, em decisão fundamentada, a execução da liminar e da sentença, dessa decisão caberá agravo, sem efeito suspensivo, no prazo de 5 (cinco) dias, que será levado a julgamento na sessão seguinte à sua interposição.

29 Lei nº 9.868/99, art. 27: Art. 27. Ao declarar a inconstitucionalidade de lei ou ato normativo, e tendo em vista razões de segurança jurídica ou de excepcional interesse social, poderá o Supremo Tribunal Federal, por maioria de dois terços de seus membros, restringir os efeitos daquela declaração ou decidir que ela só tenha eficácia a partir de seu trânsito em julgado ou de outro momento que venha a ser fixado. 
O que torna isso possível é admitir que as autoridades julgadoras possam indicar consequências relativamente imprecisas. ${ }^{30}$ Os estados adiantados devem ser certos ou prováveis, o que significa dizer que, no segundo caso, as consequências indicadas na decisão podem não ocorrer. O que se requer é que se indique tanto elas quanto sua evidenciação empírica, e que a probabilidade de sua ocorrência seja significativa.

Daí a segunda pergunta: (ii) se não se exige que as consequências sejam precisas - pois seria impossível -, então a norma se cumpre de modo retórico? Basta abrir capítulo na decisão, copiar-e-colar parágrafos sobre "indicação das consequências", e a exigência teria sido cumprida? Neste caso, o art. 21, caput, não traria ganho na racionalidade da invalidação, mas levaria a que o estilo da decisão fosse alterado.

Resposta: há uma falsa dicotomia na argumentação que opera apenas com "consequências inteiramente precisas" e "consequências meramente retóricas". Existem consequências que, se escapam da retórica, também não chegam à exatidão. São as consequências exigidas pelo art. 21. (Claro que consequências certas, acaso existentes, também devem ser indicadas. Mas essas não causam o problema em discussão.)

Além disso, há ganhos mesmo com a alteração do estilo da decisão. É que mudar a gramática das decisões é mudar - um pouco - o mundo das decisões. $\mathrm{O}$ julgador que buscar indicar consequências administrativas e jurídicas para fundamentar a invalidade está sendo educado e constrangido por uma nova gramática. A retórica das consequências é melhor do que a retórica dos princípios, pois, como apela a estados da realidade, pode ser falseada. ${ }^{31}$ Uma coisa é discutir, à luz da decisão de licenciar o empreendimento, a "dimensão objetiva do direito fundamental à dignidade da pessoa humana enquanto dever de proteção"; outra é discutir se o estado de coisas A ("os peixes vão morrer na lagoa") é preferível ao estado B ("a hidroelétrica não será construída e provavelmente faltará energia"). Consequências jurídicas e administrativas podem ser muita coisa, mas são menos coisas do que, por exemplo, a vis expansiva dos direitos fundamentais ou a dignidade da pessoa humana. A retórica das consequências é aparentemente menos efetiva do que a retórica dos princípios. Bom para todos.

\footnotetext{
E, portanto, relativamente precisas.

Pode-se discutir, num exercício empírico orientado a consequências que incorpore, por exemplo, um dado a respeito de pesquisas, sobre a credibilidade da instituição que a realizou, o tamanho da amostra, eventuais vieses, o valor da regressão estatística etc.
} 
Vamos à última pergunta: (iii) como poderá ocorrer o controle judicial a respeito das normas extraídas do art. 21 da LINDB? ${ }^{32} \mathrm{O}$ controle deve ser feito, de início, sobre se consequências foram indicadas, ou, caso não, sobre se houve justificativa para a ausência. Quanto à qualidade do prognóstico, sugere-se que o controle se dê de modo fraco, ou seja, como se houvesse presunção relativa a favor da validade das consequências indicadas na decisão. É que a revisão judicial, que ocorre a posteriori da prática da invalidação, conta com o benefício da informação trazida pelo tempo. Hindsight is the best sight: quem vê depois vê melhor - mas é injusto julgar os pioneiros com os óculos da experiência. Além disso, controle judicial intenso a respeito das consequências poderia tornar as coisas ainda piores. O hipercontrole não se quebraria, mas poderia se tornar ainda mais irracional. ${ }^{33}$

Claro que consequências manifesta ou deliberadamente erradas invalidam a invalidação. O critério do controle judicial pode, ademais, ir de fraco a médio quando se tratar da análise da indicação de consequências administrativas ligadas à expertise do autor da invalidação. A ANS invalida norma relativa a credenciamento de plano de saúde. Ao fazê-lo, não indica consequência administrativa óbvia (por ex., sobre como ficará a situação dos hospitais credenciados com base na norma extinta). É decisão incompleta, que deixa de indicar consequência extraída da atribuição funcional do autor da invalidação. O controle pode ser, aqui, menos deferente.

Falemos, agora, acerca do controle judicial sobre o exercício do dever de regularização proporcional. Em primeiro lugar, deve-se perguntar se, sendo hipótese, ele foi exercido. Depois, deve-se controlar as condições oferecidas para seu exercício. A letra da lei indica quatro critérios: a proporcionalidade; a equanimidade; a inexistência de prejuízo aos interesses gerais; a não imposição de ônus ou perdas anormais ou excessivas aos atingidos. Explica-se.

A intensidade judicial do controle sobre o dever de regularização proporcional deve ser fraca. A invalidação é antes análise a respeito do erro do ato, negócio, norma ou processo do que reflexão a respeito de seus efeitos ou de como ele pode ser salvo. O edital exige que licitantes apresentem propostas com páginas rubricadas. A decisão de invalidação de certa proposta não indica a existência de dever de regularização - banal - consistente na abertura

32 Como se trata de lei federal, o descumprimento da norma poderia justificar, por exemplo, o provimento de recurso especial.

33 O controle judicial invalidaria a decisão de invalidade cujas consequências não foram adequadamente indicadas, e, ao fazê-lo, haveria de indicar as consequências da invalidação da invalidação. 
de prazo para que o desclassificado rubrique a página faltante. É decisão que viola o art. 21, parágrafo único.

Os parâmetros para a estruturação do dever de regularização são os da proporcionalidade. A regularização deve adequada à finalidade de restauração da legalidade ("adequada"); exigindo o menor sacrifício em comparação a possibilidades equivalentes ("necessária"); "valendo a pena" num cálculo de custos e benefícios ("proporcional"). A noção de regularização equânime está contida na de regularização proporcional (dentro da proporcionalidadenecessidade). A ideia de ausência de prejuízo aos interesses gerais está contida no subleve da proporcionalidade estrita. A não imposição de ônus anormais ou excessivos está contida na proporcionalidade-necessidade.

A regularização deve ser adequada: para a restauração da validade de decreto de utilidade pública, na desapropriação, deve-se indicar republicação, e não compra e venda. A regularização deve ser necessária: ergue-se hospital fora do gabarito; entre demoli-lo, ou obrigar a empresa a construir praça, opta-se pela segunda opção. ${ }^{34} \mathrm{~A}$ regulação deve ser proporcional em sentido estrito: verificam-se, no último mês de vigência, contratos temporários (art. 37, IX) celebrados com base em lei inconstitucional. Enquanto isso, concurso público para os mesmos cargos está para ser concluído. Os efeitos dos contratos devem ser mantidos até a posse dos aprovados.

Resumindo o item: o controle judicial acerca da indicação de consequências deve ser razoavelmente deferente a como foram afirmadas - para que a indicação de consequências não se torne, de listagem de efeitos certos ou prováveis, retórica defensiva do julgador. Ao mesmo tempo, invalidações devem assumir relativa responsabilidade tanto pelo estado de coisas que se lhes sucede quanto pela reestruturação da normalidade. Entre o Fiat Justitia, pereat mundus e a retórica anódina das consequências, deve-se optar por um consequencialismo consequente.

\section{Encerramento}

Ao final deste estudo, é possível sintetizar suas conclusões na forma a seguir.

34 Está-se assumindo que a normativa municipal contempla a possibilidade da realização de acordos substitutivos de penalidades nos termos indicados no enunciado. 
1. O consequencialismo jurídico chegou de vez ao Direito brasileiro. Diversos dispositivos da LINDB incorporam exigências da consideração de consequências que é seu sentido mínimo. Tal propósito se dá de modo reativo à cultura do hipercontrole público que tomou conta do Brasil. Como toda cultura, ela não é só o que está nas normas, mas é, antes de tudo, um modo de se compreender e de se fazer o controle público a partir de cinco aspectos: o controle como (i) vagueza; como (ii) opinião; como (iii) performance; como (iv) disputa; e, afinal, como (v) incremento. O hipercontrole não parece ser bom para a sociedade, e é em parte contra ele que se afirma a alteração recente da Lei de Introdução.

2. Tomando por base de estudo o art. 21, é de se ver que seu caput impõe que toda decisão que decretar a invalidade de ato, contrato, ajuste, processo ou norma administrativa deverá indicar expressamente suas consequências jurídicas e administrativas. Importa identificar, então, o que são consequências jurídicas e consequências administrativas. Consequências não são palpites do julgador; são estados de fato e de Direito (i) admissíveis pela Constituição de 1988 e exequíveis; (ii) certos e prováveis, mas não apenas plausíveis; (iii) imediatos e imediatamente futuros, mas não remotos no tempo; e para os quais se possa indicar (iv) alguma base, lógica ou empírica, de evidenciação. Consequências jurídicas estão associadas à interpretação ou à aplicação do Direito; consequências administrativas referem-se à atuação pública.

3. A norma exige que as consequências sejam expressamente indicadas pelo julgador. Mas não ele não deve - porque não teria como - indicar todas as consequências jurídicas e administrativas da invalidação, mas, apenas, as mais importantes, seja em termos econômicos, político-administrativos e/ou sociais. Caso não existam, o julgador deverá informá-lo. Como instituições distintas possuem expertises distintas, espera-se que sua indicação reflita isso. Claro que, para cumprir adequadamente a norma, o julgador poderá, a depender da complexidade do caso, socorrer-se de técnicas intra e extra processuais de diálogo. A indicação das consequências pode ocupar capítulo final na decisão; decisões em massa podem justificar argumentações em série, mas o que importa é que sejam evidenciadas com suficiente base empírica, rigor lógico, ou técnica jurídica.

4. O art. 21, parágrafo único, permite a construção de duas normas. A primeira, norma que impõe dever formal quanto à fundamentação de certas decisões administrativas ou judiciais (o julgador deve indicar as condições para a regularização pós-invalidade); a segunda, norma a respeito do conteúdo dessas decisões (o próprio dever de regularização). Regularização é a 
identificação, para envolvidos e terceiros, dos efeitos pós-invalidação; ou é a construção das condições de possibilidade da validade jurídica do ato, negócio, processo ou norma. O dever de regularização filtra-se pelo dever de proporcionalidade; uma das formas mais imediatas de seu exercício é pela criação de períodos de transição.

5. Três difíceis questões cercam a interpretação e a aplicação do art. 21, caput, e parágrafo único: (i) será que órgãos e tribunais administrativos, cortes de contas e o Judiciário são capazes de adiantar consequências? (ii) Será que, por força de exigência suprarrogatória, o cumprimento do art. 21 tornar-se-ia mera retórica? (iii) Como poderá ser feito o controle judicial do art. 21? Pois bem: em resposta a (i), o fato é que a exigência não será suprarrogatória se se esperar que o julgador indique consequências relativamente imprecisas (e, assim, relativamente precisas). Aliás, fatoé que diversas normas exigem que autoridades julgadoras considerem e adiantem consequências - e os resultados têm sido, na média, aceitáveis. Em relação ao (ii) cumprimento retórico do dever consequencialista, a verdade é que há falsa dicotomia entre "consequências inteiramente precisas" e "consequências meramente retóricas". Existem consequências que, se escapam à retórica, também não chegam à exatidão. São as consequências exigidas pelo art. 21. Além disso, há ganho mesmo com a simples alteração do estilo da decisão. A retórica das consequências é melhor do que a retórica dos princípios, pois, como apela a estados da realidade, pode ser verificada/falseada.

6. Quanto ao (iii) controle judicial do art. 21, ele deve se perguntar, de início, se as consequências foram indicadas (ou justificadas). Depois, em relação à qualidade do prognóstico, deve incidir controle fraco, como se houvesse presunção relativa a favor da validade das consequências indicadas na decisão. É que a revisão judicial possui status epistêmico qualificado em relação à decisão de invalidação: quem vê depois, vê melhor - e é injusto julgar os pioneiros com os óculos da experiência. Mas, para além disso, decerto que consequências manifesta ou deliberadamente erradas invalidam a invalidação. Quanto ao controle do exercício do dever imposto pelo parágrafo único: deve-se, de igual modo, perquirir-se se, sendo hipótese, foi exercido. Então, controla-se, sob critério fraco, a proporcionalidade das condições oferecidas para seu exercício.

Buscou-se, aqui, trazer visão modesta, mas segura, acerca das possibilidades de incidência prática do art. 21 e de seu parágrafo único. Imaginá-lo 
panaceia é condená-lo à irrelevância. Imaginá-lo irrelevante é condenar-se à sutil irracionalidade dos nossos dias.

\section{Referências}

AFONSO DA SILVA, Virgílio. O proporcional e o razoável. Revista dos Tribunais, n. 728, 2002.

ALEXY, Robert. On Balancing and Subsumption: A Structural Comparison. Ratio Juris. v. 16. n. 4, 2003.

BARROSO, Luís Roberto. Temas de Direito Constitucional. 2. ed. Rio de Janeiro: Renovar, 2006. t. I

DARWALL, Stephen. (Ed.) Consequentialism. Nova Jérsei: Blackwell Publishing, 2008.

FONTE, Felipe de Melo. Jurisdição constitucional e participação popular: o Supremo Tribunal Federal na era da TV Justiça. Rio de Janeiro: Lumen Juris, 2016.

HALACHMI, Arie. Accountability Overloads. In: BOVENS, Mark; SCHILLEMANS, Thomas; GOODIN, Robert. (Eds.) The Oxford Handbook of Public Accountability. Oxford: Oxford University Press, 2014.

LARENZ, Karl. Metodologia da Ciência do Direito. 3. ed. Lisboa: Calouste Gulbenkiam, 1997.

MARQUES NETO, Floriano; DE PALMA, Juliana Bonacorsi. Os sete grandes desafios do controle da Administração Pública. In: PEREZ, Marcos Augusto; DE PALMA, Juliana Bonacorsi. (Coord.) Controle da Administração Pública. Belo Horizonte: Fórum, 2017.

MENDONÇA, José Vicente Santos de. Direito Constitucional Econômico: a intervenção do Estado na economia à luz da razão pública e do pragmatismo. 2. ed. Belo Horizonte: Fórum, 2018.

OLIVEIRA, Carlos Alberto Alvaro de. Poderes do juiz e visão cooperativa do processo. Revista de Direito Processual Civil. Curitiba: Gênesis, 2003.

POTIER, Camille. Les présomptions de causalité. Paris: Université de Paris I Pantheon Sorbonne, 1996. 
PULIDO, Carlos Bernal. El principio de proporcionalidad y los derechos fundamentales. Madri: Centro de Estudios Políticos y Constitucionales, 2007.

SARMENTO, Daniel. Interpretação constitucional, pré-compreensão e capacidades institucionais do intérprete. In: SOUZA NETO, Cláudio Pereira; SARMENTO, Daniel; BINENBOJM, Gustavo (Orgs.). Vinte anos da Constituição Federal de 1988. Rio de Janeiro: Lumen Juris, 2009.

SCHREIBER, Anderson. Novos Paradigmas da Responsabilidade Civil: da erosão dos filtros da reparação à diluição dos danos. 6. ed. Rio de Janeiro: Libgen, 2013.

SUNDFELD, Carlos Ari. Direito Administrativo para céticos. 2. ed. São Paulo: Malheiros, 2015.

. Uma lei geral inovadora para o Direito Público, Jota. 30 out. 2017. Disponível em: <https://www.jota.info/opiniao-e-analise/colunas/controlepublico/uma-lei-geral-inovadora-para-o-direito-publico-31102017>. Acesso em: 15 set. 2018.

SUNSTEIN, Cass; VERMEULE, Adrian. The Morality of Administrative Law. Harvard Law Review, v. 2018. 